\title{
The effectiveness of movement playing program on developing movement intelligence (one type of multiple intelligences) for children at early childhood stage
}

\section{Mena Sameh Abo Hashema}

Associate professor for Educational Programs and Curricula for Early childhood in Kindergarten Department, Education College, Helwan University

Abstract:

the research aims to identify the impact of a proposed movement play program on the development of movement intelligence for children in early childhood as one of the types of multiple intelligences, The researcher used the experimental method using the experimental design of two groups, one experimental and the other an officer, the sample number of 40 children aged (5-6) years and divided into two equal groups, one experimental and the other officer and the strength of each group (20) children and children.The results of the research were as follows: The designed program has contributed to increasing and raising the level of movement intelligence in early childhood children, There is an improvement in the children of the experimental group, which was applied to them movement play program higher than the children of the control group, which underwent the program of movement activity followed within the school in the level of movement intelligence.

\section{Introduction :}

Early childhood is considered the cornerstone for building the future .It is the most important stage in the life of any man. It is the hope of this society to build best future. Child is the basis in which the future life of the society is constructed, so concerning with him is really concerning with the nation future . The stage of early childhood is considered the composition period of the individual life that is crystallized and appeared it's features in their next life stages . So, this period is considered the most important next development stages, since the properties of the child development in this stage are considered a planting for the child personality, the progress of it's development and it the bases in which the personality pillars are rested, because what happens of development is difficult to change later .( Mona El Azhary, Mona Abou Hashima 2019 : 2021 ) .

Hoda Qenawy ( $2004: 19$ ) adds that early childhood stage is the most fertile educational and learning stage in forming and composing the personality, because it is an educational stage in which learning is cause automatically and paved the way for the educational process in the future, so it is considered a decisive stage in forming the personality bases, the path of it's physical, motor, sensory, mental, perceptive , linguistic , social, ethical , emotional, aesthetical , spiritual and skilful development .

So ,( both Jehan Emara, Mona Hashima , 2013 : 238 ) see that playing in early childhood stage is considered fundamental in educating the child and making him acquire much of experiences, skills, causing the integrated development for the child in all aspects. Through playing, the child learns what he doesn't learn 
from others . movement games ,such as climbing, swinging, running, educate him coordination between movement, mental and perception in which it's importance appears during leaning reading and writing .Playing encourages the child on developing the dialogue, engaging in construction and demolition games enforce the child self esteem .

So , the researcher saw that movement playing is one of the suitable methods in early childhood stage and selected to develop the motor intelligence as one type of multiple intelligences through the program of movement playing because it is very important for the child and it must be acquired in an early age stage .

Both (Dina Abou Al Khair , 4:2014 ), ( Jehan Al Omeran , 2006: 23) defined the movement intelligence as an intelligence concerns with physical energy and what it includes of movement potentials by which the child is characterized in this stage and it can be exploited and harnessed in the process of memorizing and deepening understanding .It is considered the ability on controlling physical movements and dealing with things proficiently . The learner deals with his body through movements, possesses a high capacity on balance and sensory motor collaboration, but the appropriate professions and majors are sport, or dance or acting or manual crafts .

The movement intelligence is considered one of intelligences types according to the theory of multiple intelligences that is expressed as the individual ability on using his body proficiently and varied in solving the problems and production for expressive purposes and targeted ones. It includes physical skills such as collaboration, balance, strength, flexibility and speed . Body is not only a tool subjected to receive the knowledge, but it is also an efficient active partner in learning process. Engaging body organs in a learning activity increases brain neurological activity, activates it's moving regions, increases Epinephrine hormone that helps in communicating information from short term memory to long term memory and the region responsible for this intelligence is cerebellum, basic adenitis and cortex (Gardner :1983). It indicated that modern theories of intelligence present in the educational aspect adopt the goal of the conventional concept of intelligence as the general mental capacity .It's theory dealt the intelligence deeply, for Gardner intelligence is (7) types and defines intelligence as a set of capacities independent from the other in which persons possess in much aspects ( Gardner, H, 1993 :30) .

The Movement intelligence : means the individual ability on using his mental capacities related with his body movements as a whole to express thoughts, feelings or moving it on a composition such as the athlete, the actor, as well as his ability on using his hands to produce things or transfer it such as sculptor, the 
mechanics and the surgery. This intelligence includes specific skills like collaboration, balance, skill, strength, flexibility, speed, feeling the body movement and it's posture and the tactical capacity ( Sabah Abdellah Ibrahim 2017 :38).

Ahmed El Sayed (2016: 2) indicated that intelligence is one of the important variables in learning movement skills for children, hence it relates closely with the mental activity and this requires quick concentration and perception .

From previously mentioned, it is shown the importance of developing the movement intelligence in the field of learning. Several of the previous studies demonstrated the efficiency of teaching with movement in teaching field in general , and in the stage of early childhood in particular, although the researcher doesn't find a study used the motor playing in developing the motor intelligence in early childhood stage, hence the present research came to determine the importance of using motor games for developing the movement intelligence for children in early childhood stage .

The researcher developed the following questions that show the basic problem of the research :

- What are the Constituents of movement playing program that helps to make the child acquires the skill of the movement intelligence?

-What is the effect of the suggested movement playing program in developing the skill of movement intelligence for children in early childhood stage?

\section{Aim of the research :}

Recognizing the effect of a suggested program of movement playing on developing movement intelligence for children in early childhood stage as one type of multiple intelligences .

\section{Procedures of the research : Methods:}

The researcher used the experimental method of the experimental design for two groups, one is an experimental group and the other is a control group , the two measurements ( the pre - post ).

\section{Sample :}

The research sample was selected randomly of (40) male and female children ranging between (5-6 years old ). They were divided into two equivalent groups, one is an experimental group, the other is a control group of ( 20 ) male and female children. The experimental group is subjected to the program of movement playing and the control group is subjected to the program of the movement activity followed in the school .( 20 ) male and female children were selected as a pilot group . 
Table (2)

The equivalence between the research groups in the variables "under research"

\begin{tabular}{|c|c|c|c|c|c|c|}
\hline & \multirow[t]{2}{*}{ The variables } & \multicolumn{2}{|c|}{$\begin{array}{l}\text { The control } \\
\text { group }\end{array}$} & \multicolumn{2}{|c|}{$\begin{array}{c}\text { The experimental } \\
\text { group }\end{array}$} & \multirow[t]{2}{*}{$\mathbf{t}$} \\
\hline & & $\mathbf{M}$ & S.D & $\mathbf{M}$ & S.D & \\
\hline & Intelligence & 107.372 & 3.451 & 106.955 & 3.796 & 0.364 \\
\hline \multirow{6}{*}{$\begin{array}{l}\text { The battery of } \\
\text { movement } \\
\text { intelligence } \\
\text { for children }\end{array}$} & Drop the ball & 50.305 & 0.801 & 50.444 & 0.907 & 0.514 \\
\hline & Turning around the circle & 49.313 & 0.757 & 49.41 & 1.046 & 0.334 \\
\hline & The color ruler and hands & 51.381 & 1.327 & 51.274 & 1.448 & 0.242 \\
\hline & Sound and movement & 48.564 & 1.154 & 48.304 & 1.05 & 0.745 \\
\hline & Walking towards the circle & 50.317 & 0.802 & 50.536 & 0.978 & 0.773 \\
\hline & Total score of the battery & 249.749 & 2.496 & 250.096 & 2.931 & 0.404 \\
\hline
\end{tabular}

The tabulated " $t$ " value at freedom degree 38 and level $0.05=2.03$

It is shown from table (2) That "t" values are not statistically significant between the experimental and the control groups indicating the equivalence of the research groups before the experiment start and that the differences between the two groups are not statistically significant because all the calculated " $t$ " values are less than the tabulated " $\mathrm{t}$ " indicating the equivalence of the research groups in these variables .

\section{Tools:}

1- Battery of measuring movement intelligence for the children ( prepared by Essam El Din Shaaban Ali, Moustafa Ahmed Abdel Wahab ) (appendix2) .

Consist of five tests ( drop the ball, turning around the circle ,the ruler and the hands, sound and movement, walking towards the circle ) that represent a battery derived from the factor analysis to measure movement intelligence for the children under 9 years .

\section{Psychometric analysis for the research tools : Validity :}

Validity coefficient :battery of movement intelligence for children :the researcher found the validity coefficient for the intelligence test by using statistical analysis " differences between groups ", where tests were applied on (20) children of the research community and outside the basic research sample, then ordered them in a descending order according to the score of everyone in the test, then find the differences significance between high quartile ( 5 children) and lower quartile ( 5 children) by using Mann-Whitney formulation to ascertain the extent of the tests " under research " to distinguish between the two groups ( higher quartile - lower quartile ) 
Table (3)

Calculating the validity coefficient for the movement intelligence tests

$\mathrm{N}_{1}=\mathrm{N}_{2}=5$

\begin{tabular}{cccccccc}
\hline \multirow{2}{*}{ The test } & \multicolumn{2}{c}{$\begin{array}{c}\text { Higher } \\
\text { quartile }\end{array}$} & \multicolumn{2}{c}{$\begin{array}{c}\text { Lower } \\
\text { quartile }\end{array}$} & U & $\begin{array}{c}\text { Significance } \\
\text { level }\end{array}$ \\
\cline { 2 - 6 } & $\mathbf{M}$ & Sum & $\mathbf{M}$ & Sum & & \\
\hline Drop the ball & 8 & 40 & 3 & 15 & 0 & 0.007 \\
\hline Turning around the circle & 8 & 40 & 3 & 15 & 0 & 0.007 \\
\hline Color ruler and the hands & 8 & 40 & 3 & 15 & 0 & 0.007 \\
\hline Sound and movement & 8 & 40 & 3 & 15 & 0 & 0.007 \\
\hline Walking toward the circle & 8 & 40 & 3 & 15 & 0 & 0.006 \\
\hline Battery total score & 8 & 40 & 3 & 15 & 0 & 0.007 \\
\hline
\end{tabular}

The tabulated " $U$ " value at freedom degree $0.05=4.00$

It is shown from table (3) that there are statistically significant differences between group 1 and group 2 in tests of movement intelligence, because the calculated (U) value is less than it's tabulated value indicating the test capacity to distinguish between the two groups indicating the test validity .

Reliability coefficient of movement intelligence battery for children :the researcher found the reliability coefficient for the intelligence test by using Test Re test, where the intelligence test was applied on the pilot group ( 20 children ), after (3) days replication with the same conditions of the first procedure .Table (4) shows the reliability coefficient of the intelligence test for children .

Table (4)

Calculating reliability coefficient for movement intelligence tests

$\mathrm{N}=20$

\begin{tabular}{|c|c|c|c|c|c|}
\hline \multirow{2}{*}{ The test } & \multicolumn{2}{|c|}{ Application } & \multicolumn{2}{|c|}{ Re-application } & \multirow{2}{*}{$\begin{array}{l}\text { Correlation } \\
\text { coefficient }\end{array}$} \\
\hline & $\mathrm{M}$ & S.D & $\mathrm{M}$ & S.D & \\
\hline Drop the ball & 50.579 & 0.82 & 50.761 & 0.95 & 0.747 \\
\hline Turning around the circle & 49.508 & 0.797 & 49.53 & 0.647 & 0.935 \\
\hline The color ruler and the hands & 51.002 & 0.896 & 50.937 & 0.857 & 0.876 \\
\hline Sound and movement & 48.655 & 1.262 & 48.688 & 1.248 & 0.865 \\
\hline Walking toward the circle & 50.569 & 0.736 & 50.584 & 0.755 & 0.961 \\
\hline Battery total score & 250.313 & 2.099 & 250.48 & 2.122 & 0.873 \\
\hline
\end{tabular}

The tabulated " $r$ " value at freedom degree 38 and significance level $0.05=2.10$

It is shown from table (4) There is a correlation between application and reapplication indicating that the test on an acceptable degree of reliability . 


\section{2- program of developing movement intelligence for early childhood stage:}

The researcher prepared a program schema for developing movement intelligence through movement playing for early childhood stage after knowing methods and bases of the educational program in general and program of movement and sport education in particular .

\section{The content of the program :}

-The researcher selected the number of games that are appropriate with the program goal.

-The researcher determined the suitable execution methods, tools and evaluation methods.

-Then, she prepared a suggested schema including the desired goals, before each goal are the games by which it is achieved, execution methods of each game individually, the necessary tools for execution, evaluation methods and at the end of each goal, the researcher left a number of blank lines.

-The researcher presented this schema to specialized judges to judge the extent of the program content appropriateness from games, the potential of achieving the program goals ,the extent of execution methods ,tools and evaluation methods .

-The researcher modified (delete or add ) games to achieve the goal according to judges opinions .

-The researcher prepared the daily schemas by which she will execute with children " the experimental research sample "of (21) daily schemas . Each meeting is half an hour. The researcher put into consideration that the daily schema includes the following :

1-An introductory section : presenting a preparation for all parts of the body and an introductory for the basic section.

2-The basic section : games that achieve the program goals for developing movement intelligence .The researcher put into consideration to present games develop more than one goal at one time and repeat some of these games in different days to achieve the goal for the child. The researcher made a verbal stress to fix concepts and information during playing .

3- The final section : the researcher presented some cool down games every time, evaluated what was practiced of games in the first section to fix it and establish movement intelligence and develop it for pre-school children .

-Appendix $(3,4)$ show the suggested schema of the program and a pattern of daily schemas .

\section{The pilot experiment :}

After designing the program schema, the researcher conducted a pilot experiment on a sample of (20) male and female children with the same circumstances and place of conducting the basic experiment .The scale was applied 
in purpose of recognizing :

-Making sure of different games suitability for children level and age at this stage . -Recognizing difficulties that children may face during the experiment to avoid them .

-Recognizing the extent of the appropriateness of different teaching methods , tools , methods of evaluation and making sure of it's suitability for developing movement intelligence .

- The pilot experiment was executed from 1/10/2018 to 18/10/2018.

\section{Executing the experiment :}

The pre measurements :

The pre measurements were conducted for the control and the experimental groups in the variables " under research "from 21/10/2018: 25/10/2018.

\section{Applying the basic experiment :}

The program of movement playing was applied on the experimental group from 4/11/2018 to 20/12/2018 as much as (3) units weekly with a total of (21) units , whereas the control group was submitted for the movement activity program followed inside the school .

The training was conducted with a temporal map that was represented in ( 21) unit for (7) weeks as much as(3) units per week, the time of the educational unit is (90) minutes .Table (5) shows the quantitative distribution of the units in which the experimental program included .

\section{Table (5)}

Distributing the training on the program of movement playing

\begin{tabular}{ccc}
\hline Serial & The statement & The temporal distribution \\
\hline 1 & Number of weeks & (7) weeks \\
\hline 2 & Total number of units & (21) educational units \\
\hline 3 & Number of units per week & $(3)$ units \\
\hline 4 & Time of application per unit & $(90)$ minutes \\
\hline 5 & Time of application per week & $(270)$ minutes \\
\hline
\end{tabular}

\section{The post measurements :}

The post measurement was conducted for the research groups ( the control and the experimental groups ) in the variables "under research " from 23/12/2018 to $27 / 12 / 2018$ as was conducted in the pre measurements .

\section{The statistical treatments :}

The researcher used SPSS program in the statistical treatments . 


\section{Results :}

Table (6)

Differences significance between the two measurements means ( the pre- post ) for the experimental group children in the research variables

$\mathrm{N}=20$

\begin{tabular}{|c|c|c|c|c|c|c|c|c|}
\hline \multicolumn{2}{|c|}{ The variables } & \multicolumn{2}{|c|}{$\begin{array}{c}\text { The pre } \\
\text { measurement }\end{array}$} & \multicolumn{2}{|c|}{$\begin{array}{c}\text { The post } \\
\text { measurement }\end{array}$} & \multirow{2}{*}{$\begin{array}{c}\text { Difference } \\
\text { means }\end{array}$} & \multirow{2}{*}{$\begin{array}{c}\text { Variance } \\
\text { percent }\end{array}$} & \multirow[t]{2}{*}{$\mathbf{t}$} \\
\hline & & $\mathbf{M}$ & S.D & $\mathbf{M}$ & S.D & & & \\
\hline \multirow{6}{*}{$\begin{array}{c}\text { Battery of } \\
\text { movement } \\
\text { intelligenc } \\
\text { e for } \\
\text { children }\end{array}$} & Drop the ball & 50.444 & 0.907 & 73.65 & 1.565 & 23.206 & $46 \%$ & 68.357 \\
\hline & $\begin{array}{l}\text { Turning around } \\
\text { the circle }\end{array}$ & 49.41 & 1.046 & 72.2 & 1.735 & 22.79 & $46 \%$ & 59.333 \\
\hline & $\begin{array}{l}\text { The color ruler } \\
\text { and the hands }\end{array}$ & 51.274 & 1.448 & 70.8 & 1.005 & 19.526 & $38 \%$ & 73.101 \\
\hline & $\begin{array}{l}\text { Sound and } \\
\text { movement }\end{array}$ & 48.304 & 1.05 & 71.95 & 1.669 & 23.646 & $49 \%$ & 51.903 \\
\hline & $\begin{array}{c}\text { Walking } \\
\text { towards the } \\
\text { circle }\end{array}$ & 50.536 & 0.978 & 72.4 & 1.465 & 21.864 & $43 \%$ & 60.848 \\
\hline & $\begin{array}{l}\text { Total score of } \\
\text { the battery }\end{array}$ & 250.096 & 2.931 & 361 & 3.88 & 110.904 & $44 \%$ & 113.653 \\
\hline
\end{tabular}

The tabulated $(t)$ value at $0.05=2.10$

It is shown from table (6) that the differences between the two measurements are statistically significant because all the calculated $(t)$ values are greater than the tabulated $(\mathrm{t})$ value indicating the differences significance between the two measurements .

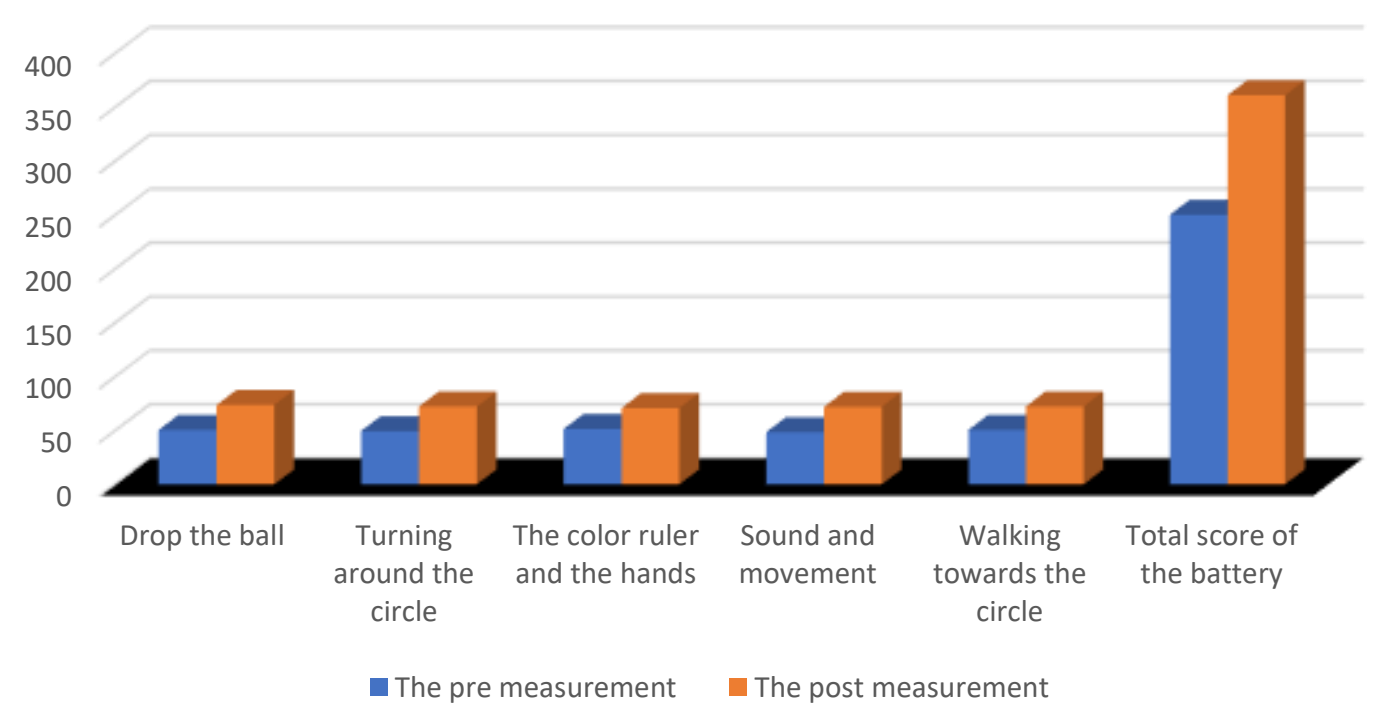

Fig. (1)

The two measurements means ( the pre- post ) for the experimental group 
Table (7)

Differences significance between the two measurements (the pre-post) between the two groups ( the control - the experimental) in the research variables

\begin{tabular}{|c|c|c|c|c|c|c|c|c|}
\hline & & & & & & & \multicolumn{2}{|c|}{$\mathrm{N}_{1}=\mathrm{N}_{2}=20$} \\
\hline \multirow{2}{*}{\multicolumn{2}{|c|}{ The variables }} & \multicolumn{2}{|c|}{$\begin{array}{l}\text { The control } \\
\text { group }\end{array}$} & \multicolumn{2}{|c|}{$\begin{array}{l}\text { The experimental } \\
\text { group }\end{array}$} & \multirow{2}{*}{$\begin{array}{c}\text { Differences } \\
\text { means }\end{array}$} & Variance & $\mathbf{t}$ \\
\hline & & M & S.D & M & S.D & & & \\
\hline \multirow{6}{*}{$\begin{array}{c}\text { Battery of } \\
\text { movement } \\
\text { intelligenc } \\
\text { e for } \\
\text { children }\end{array}$} & Drop the ball & 7.695 & 1.325 & 23.206 & 1.527 & 15.511 & $31 \%$ & 34.923 \\
\hline & $\begin{array}{l}\text { Turning around } \\
\text { the circle }\end{array}$ & 8.737 & 1.821 & 22.79 & 1.725 & 14.053 & $28 \%$ & 25.399 \\
\hline & $\begin{array}{l}\text { The color ruler } \\
\text { and the hands }\end{array}$ & 7.619 & 1.76 & 19.526 & 1.188 & 11.907 & $23 \%$ & 24.625 \\
\hline & $\begin{array}{l}\text { Sound and } \\
\text { movement }\end{array}$ & 9.086 & 1.832 & 23.646 & 2.015 & 14.56 & $30 \%$ & 23.058 \\
\hline & $\begin{array}{l}\text { Walking towards } \\
\text { the circle }\end{array}$ & 9.933 & 0.968 & 21.864 & 1.623 & 11.931 & $23 \%$ & 29.272 \\
\hline & $\begin{array}{c}\text { Total score of the } \\
\text { battery }\end{array}$ & 43.201 & 4.915 & 110.904 & 4.378 & 67.703 & $27 \%$ & 46.476 \\
\hline
\end{tabular}

The tabulated $(t)$ value at $0.05=2.10$

It is shown from table (7) that the differences between the two measurements ( the pre - post ) of the two groups ( the control - the experimental ) are statistically significant because all the calculated $(\mathrm{t})$ values are greater than the tabulated $(\mathrm{t})$ value.

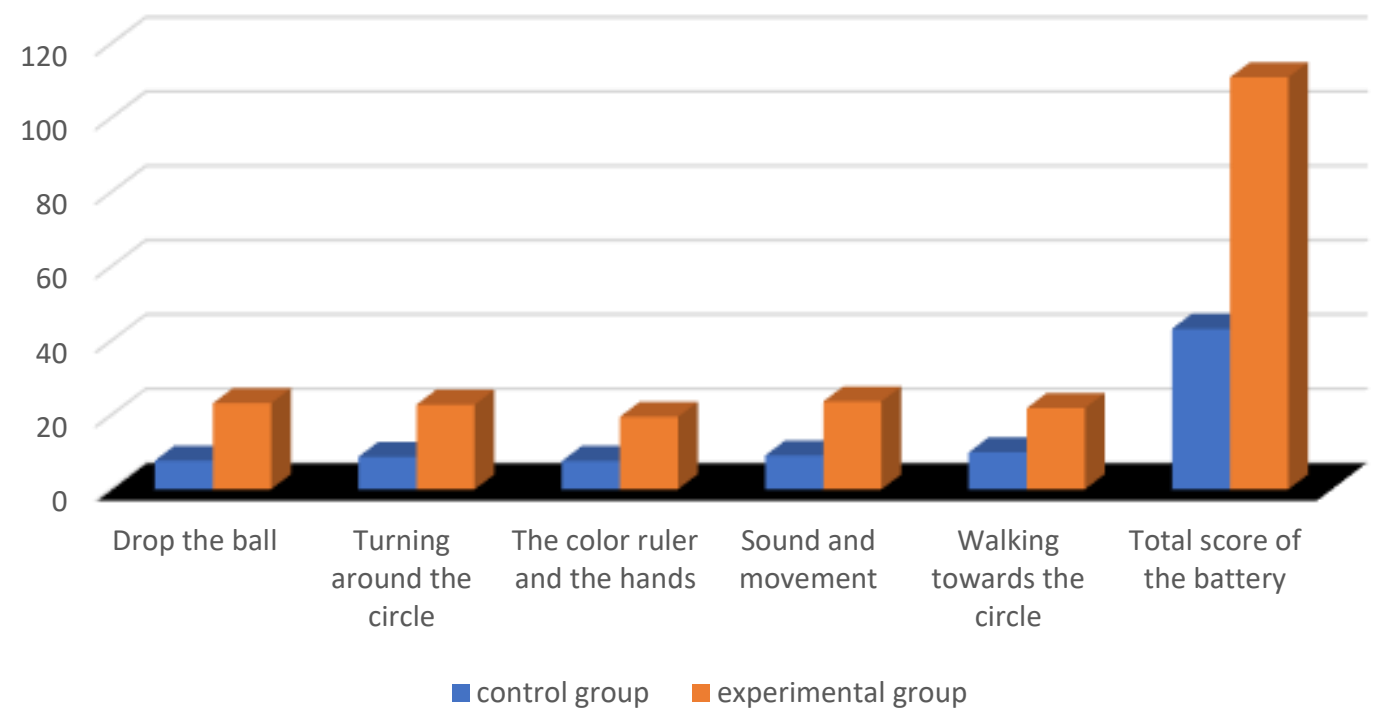

Fig. (2)

The two measurements (the pre-post) between the two groups ( the control - the experimental) 


\section{Discussing:}

It is shown from table $(6,7)$ that there is an improvement for the experimental group children in the level of the movement intelligence. The researcher attributed the improvement of movement intelligence of the experimental group children proficiently than the control group to the positive effect of movement playing program and what it includes of varied games and different tools that led to permitting the opportunity for practicing much and multiple movement experiences for the experimental group children.

This finding accorded with the study of :

Ahmed Abdel Azem Abdullah study ( 2002) "the effect of a movement education program by using micro recreation games on some movement variables and movement satisfaction of children that demonstrated the effectiveness of the suggested program in achieving some development demands in early childhood stage .

Mona Sameh Abou Hahema study (2006) : " the effect of movement playing program on developing social competency for pre - school child through using movement playing activities to increase the competency of kindergarten child in social treatment with others .

Ahmed Ali Ahmed Syam study (2011) :"the effect of using micro games on developing sensory -motor perception of the basic movement skills for kindergarten stage .The basic movement skills were represented in ) walking running - jump - throwing - dribbling -kicking ) .

Qamar Ahmed Khalil study ( 2000) that discovered the effectiveness of learning with playing for a sample of first primary graders comparing with the conventional educational methods prevalent in study classes.

Khalid Abdel Razek study (2001) that used types of playing in modifying behavior disorders for kindergarten child .

Barnett study ( 1990) found that playing has a greater effect on pre school children acquisition the capacity for solving the problems than other formal playing forms .

Mc,Carty study ( 1990), the researcher found a statistical significant relationship between imaginative playing and learning some social skills for pre school children and there is a difference in the performance level as a result of sex type .

Elise Danielle study ( 1995) :finding that children received much benefits if the time of playing practice is more than (30) minutes .

Pack Albert study (1999) : finding that preferring observation and follow up method in playing of pre-school children than the method of observation only and that constructive playing has a clear place and a great effect on the cognitive 
development for pre -school children and playing inside the house contributes in increasing and supporting functional playing, and that playing amount and its type increases and develops inside the house and collective playing are done greater and clearer outside study classes .

Ali Khudair Eabis almusawiu study ( 2016) : the researcher found several conclusions, among them are that environment has a positive effect on developing movement intelligence for children, and that kindergartens play an important role in developing this type of intelligence. He found several recommendations the most important ones are concerning with games giving for children at this age stage and the necessity of stressing on kindergartens teachers to provide the suitable class environment for the children, hence the research hypotheses were ascertained .

\section{Conclusions :}

1- The designed program of movement playing contributed in increasing the level of movement intelligence for children in early childhood stage .

2-There is high improvement for the experimental group children whom the program of movement playing was applied on them than the control group children that submitted to the program of movement activity followed inside the school in the level of the movement intelligence .

\section{Recommendations :}

1-Including programs of movement playing in kindergartens and early childhood institutions in programs of movement activities for children at this stage for it's effectiveness in improving and raising the level of movement intelligence for pre -school children .

2-Concerning with the child mental skills in kindergartens curricula for its positive role in enforcing these capacities early and discovering the talents

3-Conducting several of other similar researches on different age stages .

\section{References :}

1 - Ahmed Abdel Azem Abdullah ( 2002) "the effect of a movement education program by using micro recreation games on some movement variables and movement satisfaction of children ( 6-9 years old ), a doctoral thesis, faculty of physical education for boys , Helwan university, Cairo .

2 - Ahmed Ali Ahmed Syam study (2011) :"the effect of using micro games on developing sensory -motor perception of the basic movement skills for kindergarten stage . A master thesis , faculty of education, Zagzek university .

3 - Ali Khudair Eabis almusawiu ( 2016) :faculty of physical education , journal of physical education sciences, vol.9, no.4, Babil university, Iraq

4 - Barnett , L.A. (1990): The Contrast Between Play And Other Forms Of Learning In PreSchool Children's Problems Salving Ability "PHD" , Kansas State, University In Diss Abst.Int.

5 - Dina yaequb Abou El Khair (2014) : teaching the kindergarten children by using two 
strategies based upon the movement intelligence and spatial intelligence and their effect on Quran rememorizing, A master thesis, Middle East university, Kuwait.

6 - Elise Danielle (1995):Length Of Play Period In Relation To The Social And Cognitive Play Behaviors Of Pre-School Children, University Fullerton, California State.

7 - Gardner, H. (1983): Frames of mind the theory of Multiple Intelligences, New York: Basic Books

8 - Gardner, H. (1993):Intelligences in theory and practice. New York: Basic Books.

9 - Gehan Abou Rashed Al Omran (2006) : multiple intelligences for Bahrain students at university stage according to gender and academic specialization : is the suitable student in the suitable major ? Educational and psychological sciences, vol.7, no. 3 , faculty of education, Bahrain university .

10 - Gehan Omara , Mona Abou Hashema (2013) : the effectiveness of movement stories and movement games in developing the linguistic concepts for kindergarten child, educational and social studies, vol.19 no.3, the first section , faculty of education , Helwan university.

11 - Hazem Ahmed Mohammed Al Sayed (2016) :The effect of sport exercises presentations on some basic movement skills and movement intelligence for pre - school children , Assuit journal of physical education sciences and arts, no.43, vol.3, faculty of physical education, Assuit university .

12 - Huda Mohammed Qenawy (2004) : child and kindergarten, Egyptian Anglo library , Cairo

13 - Khalid Abdel Razek (2001) : the effectiveness of using different types of playing in modifying behavior disorders for kindergarten child, journal of childhood and development, Arabic council for childhood and development, no.3, Cairo .

14 - MC. Carty, M.A (1990): The Influence Of Imaginative Play Predisposition On The Learning Of Social Skills, University Of Toronto, In Diss Absit, Int.

15 - Mona Al Azahry, Mona Abou Hashema (2019) : movement education for pre school child, edition 2, Egyptian Anglo Library , Cairo

16 - Mona Samwh Abou Hashema (2006) : " the effectiveness of a suggested movement playing program on developing social competency for pre - school child, A master thesis , faculty of physical education for girls, Helwan university.

17 - Pack Albert (1999):An anoly sis of the social and cognitive play Behavior of kindergarten children comparing two methods of data collection untiled in the indoor and outdoor environment, university of southern, California.

18 - Qamar Ahmed Khalil ( 2000: the effectiveness of learning with playing for a sample of first primary graders , journal of Damascus university of Arts , Human and Educational sciences, vol.16, no. 4.

19 - Sabah Abdullah Ibrahim (2017) : the effect of an educational program by using micro games on developing some physical and skilful variables for kindergarten children , physical education studies and researches, no.53, pp.38-50, Mansoura university . 